\title{
New technologies: integration into education
}

\author{
Bernard Cornu
}

Institut Universitaire de Formation des Maîtres (IUFM)

Grenoble, France

\begin{abstract}
New technologies are penetrating education. But new technologies are usually simply added to other topics in schools, not really integrated. New technologies are not widely used in schools as one would have expected some years ago; the generalization of new technologies has become one of the main problems, and integration is now a necessary step. Integration can be defined as "combining parts in a whole". In this paper, I examine the question of integration in several aspects: hardware and software integration, integration into disciplines, integration in teaching and learning. In particular, I discuss the evolution of the profession of a teacher towards an "integrated" profession, that is with many different competencies which are not only juxtaposed, but which are interact, and I draw some conclusions for teacher education. Education now needs to design integrated environments; this is a huge task for educators. This paper poses a number of questions about integrating new technologies into education, in order to evolve from juxtaposition to integration. Only when new technologies are integrated, will their use become natural, easy, and will they have a wide effect on teaching and on learning.
\end{abstract}

Keywords: integration, organisation, policy, social issues, teacher education 


\section{INTRODUCTION}

In most countries, education has been penetrated by computers and informatics. Schools have computers, a large number of teachers use computers and new technologies, and textbooks often have some parts devoted to new technologies. Many experiments have been done, many journals are published about new technologies in education, many conferences are held about that topic. The development of new technologies in education, however, is not as wide spread as one would have thought ten years ago, and a lot of progress has still to be made. Computers are more and more sophisticated, but also cheaper and cheaper, and more easy to use and to carry. Software is increasingly user-friendly, and adaptable to educational uses. Teachers are offered pre- and inservice training. Meanwhile in society, new technologies are developing quickly, and are used in many domains in everyday life. So, why are new technologies not as widely used in education as one would hope?

There are two major reasons : generalization and integration.

Generalization: Much effort has been expended in order to develop hardware and software adapted to education. A lot of very interesting experiments and research have been carried out about computers in education. But computers in schools are used only by some teachers, the most enthusiastic ones, who have to spend hours and hours, nights and weekends, in order to incorporate computers in their teaching. We now need all teachers and all pupils to use computers in teaching and learning. We need to generalize what is now done by only some teachers and some pupils. Of course, this raises a number of questions. How can the use of new technologies in education be generalized? What are the necessary conditions? Are there helping factors? Certainly, some answers can be provided by appropriate equipment, and by appropriate teacher education; but they are not enough.

Integration: New technologies are most of the time just added to other topics in schools. Informatics courses are added to the curricula; a computer room is added to the other rooms in schools; time for new technologies is added to the pupils time-table; a chapter about the use of new technologies is added to the school books; computer activities are added to the other activities in the classroom. But they are time-consuming, and the teacher must then squeeze the rest of the 
curriculum into the remaining time. We now need a clear integration of new technologies in school, not an addition: integration in subjects, integration in teaching, integration in learning, integration in the school, integration in the profession of the teacher.

The question of integration is wide open; the aim of this paper is to focus on this aspect of new technologies in education, and to raise some questions.

Certainly, there is a link between generalization and integration. If only integration was achieved, generalization would follow; and conversely, generalization of the use of new technologies by teachers and pupils would impose integration.

\section{THE GROWTH OF INTEGRATION}

What does the word "integration" mean? The dictionary says: "combine parts in a whole". We will then have to study what the parts are, and what the whole could be, and which whole we would wish for. The dictionary also says: "incorporation of new elements in a system", or "co-ordination of the activities of several organs, for a harmonious working". There are many examples of integration. One speaks about the "integrated circuit", "integrated kitchen", "integrated processing" and "integrated management". Integration is also often used in the sense of the opposite of segregation, bringing everybody into equal membership in society, disregarding race or religion. In France, some years ago, we had a minister of integration.

Computers and software are more and more integrated within themselves: the evolution of computers is towards more integrated material. Computers now integrate many different facilities, and you can find notebooks with an integrated screen, disc driver, printer and modem. The size and compactness of computers allow for more integrated hardware. But what also makes computers increasingly integrated is both the software and the system. You can now use simultaneously different software and facilities. Integrated software provides word processing, spreadsheet, data files, which you can use at once and which are linked to each other. Many specialized applications are now facilitated by integrated software devoted to that particular field, for example computer assisted design, computer and music. CD-ROM, videodiscs, have provided a new step in integration, giving the possibility of mixing words, numbers, pictures, sounds and movies, and processing them as objects in a similar way. Thus you can cut and paste a part of a text, a part of a movie, 


\section{Integrating information technology into education}

a part of a picture, a part of a piece of music. You can incorporate music in a text, in a picture, you can incorporate a video in a text. Texts, sounds, pictures, are considered as similar objects, to which you can apply the same operations. In that sense, they are integrated: as parts, they have been combined into a whole.

Multimedia is an example of integration. It is not only the possibility of using different media, but the possibility of linking them, making them bound up with each other, that is significant.

Information and communication technologies are now linked and integrated. Computer, telephone, fax and television. Allow us to imagine in which direction integration will develop. Many tools which seem independent are becoming linked, fields which were originally distinct are now closely overlapping, such as informatics and audio-video. Many of us have at home a radio, a television, a tape recorder, a video, a compact disc system, a telephone, perhaps a fax. All these materials are generally distinct. Increasingly, however, we connect them together through a huge quantity of wires. This is the first step of integration. And probably all these objects will one day be integrated into a unique one. The old black vinyl records for music are disappearing, giving place to compact discs. Books, which take so much space, will be in compact disc format and linked to our computers. Electronic dictionaries and encyclopaedias are already providing us with good examples.

But "integration in themselves" does not mean that new technologies are integrated in society. That is another step yet to be taken.

New technologies will be integrated in society when they will no longer be a supplementary tool, added to what existed before, but when will take their place and become natural and "invisible". It is already the case for some technologies such as telephone, television and pocket calculators. Fax and "Minitel" are starting to be integrated. Computers are becoming integrated for some partial or specialized uses such as automatic bank cash, machines delivering train tickets, and some household apparatus, they but are certainly not totally integrated in society. Nevertheless, evolution is clearly moving towards an integration of new technologies in society.

But what about education? The integration of new technologies in society should imply their integration in education. I will try to describe different aspects of this integration. 


\section{INTEGRATION IN EDUCATION}

New technologies are integrating into disciplines and more disciplines are being influenced by new technologies in an integrated way. Most significantly, some fundamental concepts are evolving and new concepts are appearing under the influence of new technologies. These new technologies and their own concepts are now involved in many disciplines. Researchers use new technologies in almost all subjects, and this changes the nature and the methods of the work in each subject, for instance, in mathematics the concept of proof, the concept of function and the role of computations, have changed with the use of new technologies. Indeed in many subjects, new possibilities for statistics, for data processing, for simulation and experimentation, have changed the concepts and the methods through their integration in the subject. The frontiers between disciplines have also changed under the effect of new technologies, making some of them closer.

What is true for disciplines at the research or professional level is not totally true at the education level so that disciplines as they are taught do not always use new technologies. The transposition from scientific knowledge to "knowledge to be taught" has not yet taken into account new technologies, and there is a need for reflection about the integration of new technologies in "disciplines at school" and about "integrated curricula". An important question for each of our countries is "how to design integrated curricula", that is, curricula that actually integrates new technologies?

\section{Pedagogy}

New technologies provide tools for teaching. Currently, these tools are generally used as supplementary tools besides the usual ones. Integration should eventually lead to "integrated teaching". This requires considerable reflection, not only about the way tools can be integrated, but also how "integrated pedagogy" could be designed. An integrated pedagogy uses new technologies as a fundamental component. It is not enough to integrate new technologies into pedagogy: one must design afresh an integrated pedagogy, new integrated pedagogical methods and new integrated pedagogical tools.

\section{The teacher}

The profession of a teacher should be an "integrated" one. A teacher needs many different competencies. First teachers must master the subject they have to teach. But this is not enough. They must also be able to step 


\section{Integrating information technology into education}

beyond the immediate confines of the subject and observe it from outside, know about its history and evolution, and about its applications in society. Teachers must master teaching and learning, and the didactical aspects of the transmission of knowledge. Teachers must know about pupils, their psychology, their behaviour in a group. Teachers must know about the educational system, its role in society, and the ethical aspects of the profession. All these components must not just be added, juxtaposed one to another. There are strong interactions between these components, and the teacher must integrate them and thus combine them in a whole.

It is similar with new technologies. Integration means the possible intervention in the different components of the teacher's role, in the discipline, in the transmission of knowledge, in pupil and class management. This needs both appropriate tools and appropriate scenarii. Designing them is a substantial issue. When designing new software, new tools, new strategies, all these aspects should be taken into account. New technologies themselves can help this integration, because they facilitate communication, linking and interactions.

The changes in society, among pupils' perceptions, and the evolution of new technologies, are leading to a new profession for teachers. Will this new profession be more integrated? What are "integrated teachers"? Their job is not only teaching twenty hours per week in classes. They spend as much time working outside the class. Certainly they will need an office in the school, well equipped with new technologies. They will work together with colleagues, normally in groups. They will use new technologies in the classroom. They will not only be delivering knowledge, but acting also as counsellors, advisors, organizers, leaders and managers. They will collaborate in the design, elaboration and production of tools for teaching. Thus they will be genuine intellectuals, specialists in teaching and learning, true professionals. As good professionals, they will have access to the best and most efficient tools, and they will be prepared to use these tools and be able to make informed choices of the most appropriate ones for them.

New technologies imply new competencies for the teacher, but also make the traditional competencies more necessary, more linked to one another, and more integrated. An important area of study is how new technologies will be integrated into the profession of teachers.

\section{Learning}

From the learner and learning point of view, integration leads to another series of questions. The different components of learning should not be separated, but linked and integrated. How can new technologies help for 
an integrated learning? How can new technologies help to take into account the learners' approach? How can new technologies help in individualizing teaching and learning?

For example, evaluation is generally not integrated in learning; rather it is often considered as a control after the learning. Everybody knows that evaluation could contribute in learning, and could be a part of learning. Do new technologies help to integrate evaluation in learning ?

The meeting of "neurosciences" and "cognisciences" with new technologies provides an opportunity for integrating new technologies into teaching and learning. It can allow for a modelling of knowledge and modelling of the learning, and then implementing, experimenting and simulating them, leading to new tools and strategies for teaching and learning. Work in this field has already begun.

\section{Integrated environments}

The integration of new technologies requires newly designed integrated environments. In schools, hardware should not only be placed in specialized rooms, but be integrated in the usual rooms. In such a room, new technology tools should be available easily, without particular preparation; they should be "invisible", in the sense that a telephone is "invisible" in a house, so that you don't notice it and you use it without specially thinking about it. Such an "integrated classroom" should contain basic tools such as overhead projector, video, computer, and perhaps be linked to a network. A school should also integrate new technologies, and reflection about the reality of an "integrated school" is an interesting debate. There do exist some examples in different countries. The tools and resources one uses in teaching need also to use new technologies. In textbooks, for instance, new technologies must not be in an additional chapter, but must be integrated throughout the book. Multimedia provides a new style of "new technologies textbooks", mixing a wide variety of data and resources. School organization in general, and details such as the pupils' timetable, need to be thoroughly integrated.

Designing such integrated environments is, however, a huge task for educators.

\section{IMPLICATIONS FOR TEACHER TRAINING}

The evolution of education, the changes in the profession of a teacher, the need for generalizing and integrating new technologies, make teacher training a pivotal point. In teacher education and training, integration is 
again an important issue. Teacher education must incorporate both knowledge acquisition, and professional and pedagogical competencies. These are not two separate fields, but need to interact. Knowledge and pedagogy must be integrated in order to build the professional ability of a future teacher. Teacher education is based both on theoretical and academic training, provided in appropriate institutions or universities, and on practical training, through schools and classes. Again, these two components of teacher education are not independent, but must interact, must be fed one by the other. It is again a matter of integration.

Future teachers do not teach the way we tell them to; they reproduce the way they are taught. So in teacher education, the methods and the pedagogical strategies which are used are at least as important as the content. This is particularly true for new technologies. In teacher education, the first need is not courses about the use of new technologies, rather the first need is to actually use new technologies in the training. Future teachers need to learn something new through new technologies, to have the feeling that new technologies brought them something they would not have acquired otherwise. It is therefore absolutely necessary to integrate new technologies into teacher education. This is a difficult question for teacher education institutions, as well for pre-service and for in-service training.

\section{CONCLUSION}

I have argued that the question of integration should be raised at many different levels: disciplines, teaching, teachers, learning, education environments and teacher training. The integration of new technologies in education needs some reflection about the educational system of tomorrow, and the nature of the school of tomorrow. In every country, in every school, we need development projects, exploring the reality of integrating new technologies. It should be a matter of policy, at the national level, as well as at the school level. Organizations such as IFIP could provide an arena for reflection, orientations and guides for good practice. Curricula, teacher training, school organization, school policies, are interrelated topics of concern.

A world wide perspective, dealing with the different questions not separately, but with a coherent and global approach, will help to improve and define an "integrated educational system". Of course, an educational system cannot be examined without reference to the other systems in society. 
I believe that we have to make a move from juxtaposition to integration. New technologies were added into the system. They were then incorporated within the system but as a distinct part, reserved for specialists. The next step is to be inside, fully integrated and institutionalized.

But integration must enable us to change and evolve. We must not integrate new technologies in our old habits, integrate our old strategies in new technologies, but we must change our minds, change the system, change the arena of problems. We must have a global and dynamic reflection about integrated tools and methods.

When new technologies are integrated into education, they will no longer be "visible". You do not notice what is integrated, you use it without thinking, it becomes as natural as a telephone or a watch.

All the papers in these conference proceedings contribute by providing examples of integration and answers to some of the related questions. In this way this conference is part of the reflection and debate which I consider essential for successful integration.

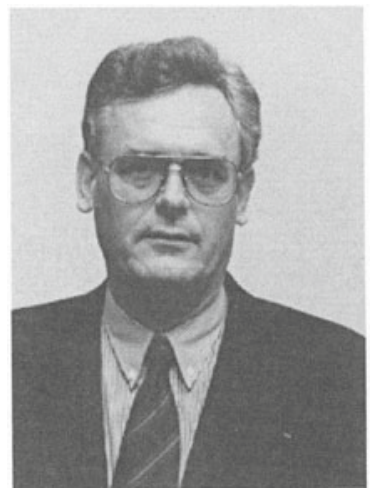

Bernard Cornu is a Mathematician at Grenoble University. He studied the influence of computers and informatics on mathematics and its teaching, and also worked in didactics of mathematics. He was the Director of the Institute of Research on Mathematics Teaching (IREM) of Grenoble, and then the head at the in-service teacher training office for the Academy of Grenoble. He contributed to the French reform of initial teacher education, leading to the creation of the University Institutes for Teacher Education (IUFM), in which all primary and secondary teachers, in all disciplines, are trained for two years. Bernard Comu is the Director of the IUFM of Grenoble, and was until 1994 the Chairman of the 29 IUFMs in France. He is the vice-chair of IFIP Working Group, 3.1 and Chairman of this Conference. 